\title{
Adjacent schwannomas originating from intercostal and sympathetic nerves
}

\author{
Kazuki Hayashi, ${ }^{1}$ Makoto Motoishi, ${ }^{2}$ Satoru Sawai, ${ }^{3}$ Jun Hanaoka
}

'Division of General Thoracic Surgery, Department of Surgery, Shiga University of Medical Science, Otsu, Japan ${ }^{2}$ Division of General Thoracic Surgery, Mitsubishikyoto Hospital, Kyoto, Japan ${ }^{3}$ Division of General Thoracic Surgery, National Hospital Organization Kyoto Medical Center, Kyoto, Japan

Correspondence to Dr Kazuki Hayashi,

hayashik@belle.shiga-med.ac.jp

Accepted 16 October 2018

\section{DESCRIPTION}

Schwannomas are the most frequent type of intrathoracic neurogenic tumour, but the presence of multiple simultaneous schwannomas is a rare occurrence. We experienced a patient initially thought to have a single schwannoma based on preoperative imaging, but who was subsequently found to have two adjacent schwannomas arising from different nerves.

A 48-year-old woman showed an abnormal shadow on chest X-ray during a medical examination. CT-guided biopsy did not provide a definitive diagnosis, and she was therefore referred to our department. Her general condition was good and her neurological findings were normal. No skin pigmentation or subcutaneous nodules were observed. Chest CT revealed a $5.5 \mathrm{~cm}$ segmental lobular tumour in the right posterior mediastinum (figure 1A) and chest MRI showed that the tumour continued from the right intervertebral foramina (figure 1B). We suspected schwannoma of the intercostal nerve, and performed video-assisted thoracoscopic surgery in the left lateral decubitus position. A lobular tumour was present in the 10th

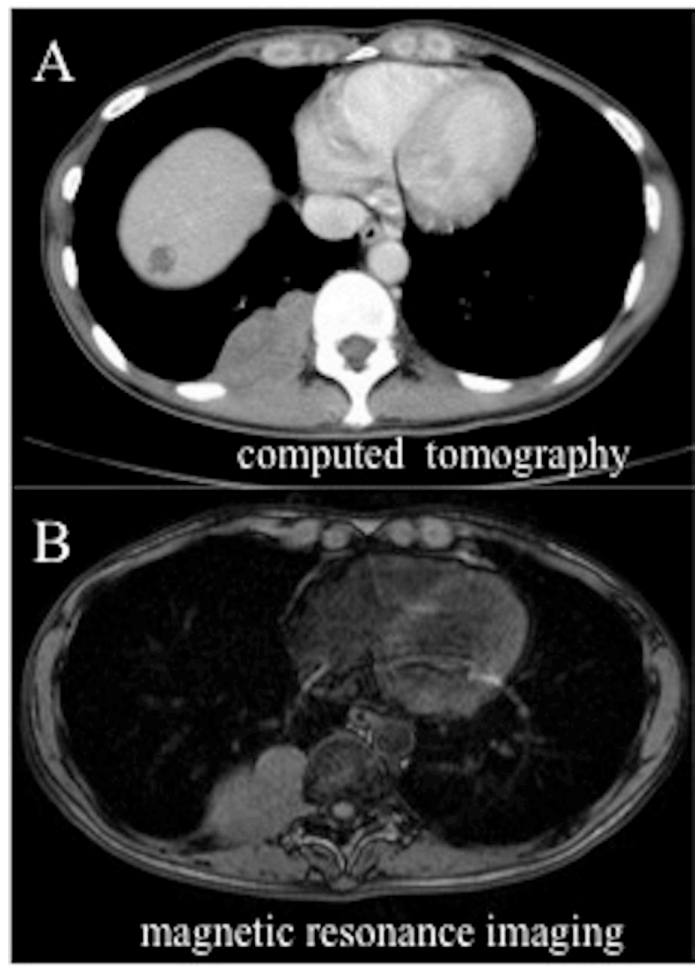

Figure 1 (A) Chest CT showing a lobular mass in the posterior mediastinum. (B) Chest MRI showing the tumour continuous with the intervertebral foramen.

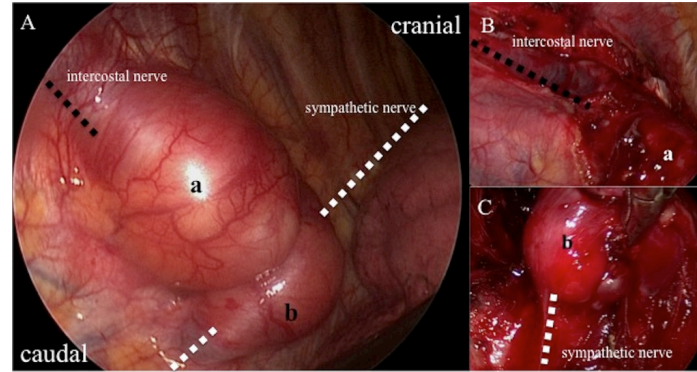

Figure 2 (A) Intraoperative findings showing the tumour located in the 10th intercostal space and appearing segmented ( $a$ and b). (B) One tumour was continuous with the intercostal nerve (black dotted line) (C) and the other was consecutive with the sympathetic trunk (white dotted line).

intercostal space (figure 2). However, while peeling the parietal pleura, the lesion was seen to comprise two distinct tumours rather than a single tumour; one continuous with the intercostal nerve and the other continuous with the sympathetic nerve trunk. Neither of the tumours invaded the surrounding tissue and both were isolated from the nerves and removed. Both tumours were schwannomas. There was no nerve resection in the high intercostal space, and no obvious neurological deficit symptoms including abnormal perspiration were observed after surgery. However, wound pain accompanied by intercostal neuralgia, as a common result of video-assisted thoracoscopic surgery, was observed for 2 weeks. The patient showed no signs of recurrence 2 years after surgery.

Schwannomas are the most common type of neurogenic tumour occurring in the thoracic cavity, but the presence of more than one simultaneously is rare. The current patient had no relevant physical findings and no family history suspicious of neurofibromatosis, which is considered as a schwannomatosis. ${ }^{1-3}$ Although the lesion was initially thought to be a single tumour based on preoperative image evaluation, thoracotomy revealed two adjacent schwannomas located side by side in the same intercostal space. Tumours derived from the intercostal nerve and the sympathetic trunk require different surgical approaches to cut the relevant nerve, and the ease and safety of the operation is greatly affected by the placement of the operation port. When patients present with lobular tumours on preoperative imaging, it is therefore necessary to plan the surgery considering the possibility that the tumour may comprise multiple adjacent tumours rather than one single tumour. 


\section{Learning points}

The presence of multiple schwannomas in the thoracic cavity is a rare occurrence.

- Multiple schwannomas can occur even in patients with no history of neurofibromatosis.

- The possibility of multiple adjacent schwannomas in the same intercostal space but derived from different nerves should be considered in patients who present with lobular tumours, even if initial imaging suggests that the lesion is a single tumour.

Contributors $\mathrm{KH}, \mathrm{MM}$ and SS carried out the procedure care of the patient. $\mathrm{KH}$ was a major contributor in writing the manuscript. MM, SS and JH contributed to data collection and interpretation, and critically reviewed the manuscript. All authors read and approved the final manuscript.

Funding The authors have not declared a specific grant for this research from any funding agency in the public, commercial or not-for-profit sectors.

Competing interests None declared.

Patient consent Obtained.

Provenance and peer review Not commissioned; externally peer reviewed.

\section{REFERENCES}

1 statement NC. National institutes of health consensus development conference. Arch Neurol 1988:45:575-8

2 Ogose A, Hotta T, Morita T, et al. Multiple schwannomas in the peripheral nerves. Jone Joint Surg Br 1998:80:657-61.

3 Seppälä MT, Sainio MA, Haltia MJ, et al. Multiple schwannomas: schwannomatosis or neurofibromatosis type 2? J Neurosurg 1998;89:36-41.

Copyright 2018 BMJ Publishing Group. All rights reserved. For permission to reuse any of this content visit http://group.bmj.com/group/rights-licensing/permissions.

BMJ Case Report Fellows may re-use this article for personal use and teaching without any further permission.

Become a Fellow of BMJ Case Reports today and you can:

- Submit as many cases as you like

- Enjoy fast sympathetic peer review and rapid publication of accepted articles

- Access all the published articles

- Re-use any of the published material for personal use and teaching without further permission

For information on Institutional Fellowships contact consortiasales@bmjgroup.com

Visit casereports.bmj.com for more articles like this and to become a Fellow 